\title{
Barriers to Current Guidelines in the Management of Pediatric Acute Otitis Media
}

\author{
Tiffanie Bourgeois' ${ }^{1}$ Catie Griffith', Ema-Chanel Johnson ${ }^{1 *}$, Betty Leblanc' ${ }^{1}$ Brooke Melancon' \\ 'Northwestern State University of Louisiana in Shreveport
}

Article Info

\section{Article Notes}

Received: May 4, 2019

Accepted: June 25, 2019

\section{${ }^{*}$ Correspondence:}

Ema-Chanel Johnson, Student enrolled at Northwestern State University of Louisiana, Shreveport, LA, USA; Telephone No: (318) 572-2932; Email: Emachanel@yahoo.com.

(c) 2019 Johnson EM. This article is distributed under the terms of the Creative Commons Attribution 4.0 International License.

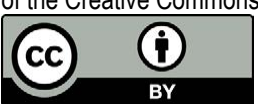

\section{Keywords}

Acute Otitis Media

Uncomplicated AOM

Severe AOM

Nonsevere AOM

Otitis Media with Effusion (OME)

Middle Ear Effusion (MEE)

Otorrhea

Otitis Externa

Initial antibiotic therapy

Initial Observation

Watchful Waiting (WW)

\section{Abstract}

This review's purpose is to identify barriers on adherence of treatment guidelines in the management of pediatric Acute Otitis Media (AOM). The American Academy of Pediatrics (AAP) and American Academy of Family Physicians (AAFP) released revised AOM practice guidelines in 2013. These guidelines address diagnosis and management of AOM in healthy pediatric patients from six months to 12 years of age. AOM is the most common reason children are prescribed antibiotics ${ }^{1}$. Previous and continued antibiotic overuse presents increasing problems pertaining to antibiotic resistance, overall children's health, and healthcare costs ${ }^{2}$. This guideline recommends treatment should be based on presenting signs and symptoms with severity being key in treatment, while conserving antibiotic use. This guideline includes diagnostic criteria, promotes the use of pneumatic otoscopy, and provides appropriate treatment regimens based on findings. Despite this, there is evidence that these guidelines are not being followed in multiple disciplines that provide care to this population.

A comprehensive review of the literature obtained from several databases, produced 650 articles after inclusion and exclusion criteria was applied. In order to include the highest possible level of research, the articles were individually reviewed, and 19 articles were included in this review. Major barriers identified included factors regarding providers, parents, AOM severity and complications, concerns for follow-up care, and other clinical related factors. This literature review identified and compares these multidisciplinary barriers in hope of understanding reasons for the lack of guideline adherence and possibly help facilitate behavioral changes to improve patients' wellbeing.

\section{Keywords defined:}

- $\quad$ Acute Otitis Media (AOM)- rapid progression of signs and symptoms of inflammatory responses of middle ear ${ }^{3}$.

- Uncomplicated AOM- AOM that does not include otorrhea ${ }^{3}$.

- Severe AOM- AOM with moderate to severe ear pain or temperature 102.2 F or higher ${ }^{3}$.

- Nonsevere AOM- AOM with mild ear pain and temperature below $102.2 \mathrm{~F}^{3}$.

- Otitis Media with Effusion (OME)- fluid in middle ear with inflammation where no acute infection signs or symptoms are present ${ }^{3}$.

- Middle Ear Effusion (MEE)- fluid in the middle ear without inflammation ${ }^{3}$.

- Otorrhea- ear discharge from external auditory canal, middle ear, mastoid, inner ear, or intracranial space ${ }^{3}$.

- Otitis externa- external auditory canal infection ${ }^{3}$.

- Initial antibiotic therapy- AOM treatment with antibiotics prescribed at initial encounter ${ }^{3}$.

- Initial observation (watchful waiting/WW)- Symptomatic relief where antibiotics are only initiated if child's condition does not improve within 48 to 78 hours after diagnosis, and a follow up plan should be in place ${ }^{3}$. 


\section{Acute Otitis Media Impact}

AOM will affect most children before 10 years of age. The most common risk factors include winter months, low socioeconomic status, poor nutrition, nursery or daycare attendance, bottle-feeding, flat feeding, use of pacifiers, siblings with recurrent ear infections, insufficient vaccinations, parental smoking, and poor hygiene ${ }^{4}$. Hirst and Neill $(2013)^{4}$ report that it is most common in boys and can have a viral or bacterial etiology with the most common pathogens being Streptococcus pneumoniae and Haemophilus influenzae. Evidence based guidelines are available for treatment of AOM, but they are not being followed. As medicine advances, evidenced based practice is essential to provide the best patient outcomes.

\section{Background and Significance}

AOM commonly follows an upper respiratory infection when the infection travels up the eustachian tube to the middle ear, resulting in inflammation and effusion. Exudate from the inflammatory process causes the tympanic membrane to bulge and could potentially rupture. A ruptured eardrum can leave the middle ear vulnerable to infections or injury and could potentially result in permanent hearing loss ${ }^{4}$.

Antibiotics were used as first-line treatment for AOM in the beginning of the $20^{\text {th }}$ century, resulting in a decrease in AOM occurrence and complications, but this also led to flippant, widespread use of antibiotics for anything mimicking this condition. In the 1980s, the phenomena of antibiotic resistance became evident, which has led to widespread efforts to decrease unnecessary antibiotic use $^{5}$. Later studies have suggested that antibiotics are not effective for uncomplicated cases of AOM and may cause unwanted side effects including diarrhea, vomiting, and rashes which lead to poor outcomes. This is especially true in the pediatric population because children tend to have relatively more severe side-effects when compared to adults ${ }^{4}$.

According to Hirst and Neill $(2013)^{4}$, one of the most serious complications that may arise from untreated or irresponsive AOM is mastoiditis, an infection of the mastoid bone, which should be suspected when the child presents with earache, otorrhea, pain, headache, fever hearing loss, redness, and ear swelling; this condition should be immediately referred to an ear, nose, and throat specialist. They also report other potential, but very rare, complications including chronic suppurative otitis media, eardrum perforation, cholesteatoma, facial nerve paralysis, and meningitis. Some more serious and very rare complications of untreated AOM reported by Thomas et al. (2014) ${ }^{5}$ includes labyrinthitis, sinus vein thrombosis, epidural abscess, subdural abscess, cerebral abscess, and Gradenigo syndrome. Again, although there is some risk of complications associated with not treating AOM with antibiotics, the occurrence is very rare, especially in comparison to the emerging risks of antibiotic resistance.

\section{Current Guidelines}

In 2004, the AAP and AAFP released guidelines which include recommendations for diagnosing, managing, and preventing $\mathrm{AOM}$ in healthy children six months through 12 years of age, excluding children with underlying clinical conditions such as presence of tympanostomy tubes, anatomic abnormalities, genetic conditions, immune deficiencies, and the presence of cochlear implants ${ }^{3}$. The guidelines are intended to assist providers from a variety of disciplines, including nurse practitioners, in the appropriate diagnosis and management of AOM in clinical settings where these patients will seek care.

Some illnesses have specific defining characteristics, also known as gold standards, but this has not been made apparent for AOM. Efforts have been made to create videography or photography through otoscopy and use of tympanocentesis for culture and sensitivity analysis can aid in more definitive diagnosis of AOM, but these measures are not routinely utilized, and sometimes they are not feasible in this population. AOM can resemble otitis media with effusion (OME) and can be difficult to differentiate on examination. Clear guidelines for diagnosing AOM can aid a provider in distinguishing these differences. A normal tympanic membrane (TM) should appear pearly gray, translucent, ground-glass appearance, mobile, and specific landmarks of the internal ear should be easily visualized ${ }^{3}$. Based on the AAP and AAFP guidelines, symptoms in the pediatric population may include fever, intense ear pain, tugging/rubbing/holding ear, excessive crying, or changes in sleep; however, diagnosis should be made based on stringent otoscopic changes ${ }^{3}$. The guidelines also state that otoscopic signs include cloudy, bulging, red, or yellow TM and TM with decreased mobility, assessed by using pneumatic otoscopy, a standard tool for diagnosing otitis media (OM). Accurate diagnosis of ear infections is key to providing appropriate care with the use of these evidence-based guidelines.

The guideline's recommendations for initial management for uncomplicated AOM depends on the age of the patient and severity of signs or symptoms. More severe symptoms include otoscopic examination findings, high pain level, and temperature over 102.2, or otalgia beyond 48 hours. Criteria for antibiotic use in children six months to two years old include otorrhea with AOM, unilateral or bilateral AOM with severe symptoms, and unilateral/ bilateral AOM without otorrhea ${ }^{3}$. The guidelines also state that if the child is over 2 years of age, antibiotics should only be used for otorrhea with AOM, unilateral or bilateral AOM with severe symptoms. What is unique with this population is that watchful waiting can be used in unilateral/bilateral AOM without otorrhea with provider discretion ${ }^{3}$. 
Watchful waiting is defined by Lieberthal et al. $(2013)^{3}$ as initial observation of uncomplicated AOM with planned follow up or an alternative plan if the child's symptoms worsen. The guidelines also state that it is important when using watchful waiting for AOM to provide a rescue antibiotic if necessary. This can be done in two ways, a "wait-and-see" prescription at the initial office visit where the caregivers are given instructions to fill the prescription if the child worsens or fails to improve in 2-3 days. The second way may include the provider can withholding a prescription at the initial encounter but instruct the caregiver to call or return to the clinic if the child worsens or does not improve within 2-3 days ${ }^{3}$. Of course, this approach of AOM management may require increased caregiver education and a trusting relationship between the provider and caregiver.

Current guidelines for antibiotic treatment in the management of AOM are also included by the AAP and AAFP. Lieberthal et al. (2013) ${ }^{3}$ report that if antibiotics are indicated in AOM, as mentioned in the criteria previously, providers should prescribe amoxicillin for treatment if the child has not consumed amoxicillin in the past 30 days, does not have purulent conjunctivitis, and is not allergic to penicillin; if amoxicillin use in the past 30 days has occurred or AOM is unresponsive to amoxicillin, B-lactamase coverage should be used. They also recommend that if symptoms worsen or there is no response to the initial antibiotics, the clinician should consider a change in antibiotic therapy. Firstline treatment in most patients is high-dose Amoxicillin $(80-90 \mathrm{mg} / \mathrm{kg} /$ day in 2 divided doses) or Amoxicillinclavulanate $(90 \mathrm{mg} / \mathrm{kg} /$ day of amoxicillin with $6.4 \mathrm{mg} /$ $\mathrm{kg} /$ day of clavulanate in 2 divided doses) ${ }^{3}$. Amoxicillin is the recommended first-line because of its efficacy against common AOM bacterial pathogens, safety, affordability, acceptable taste, and narrow microbiologic spectrum ${ }^{3}$. Alternative initial treatment of AOM in penicillin allergic patients includes oral Cefdinir, cefuroxime, cefpodoxime, or ceftriaxone administered intramuscularly ${ }^{3}$. Alternative treatment options for antibiotic failure after 48-72 hours includes ceftriaxone or clindamycin, with or without a third-generation cephalosporin, tympanocentesis, and/ or specialist consult ${ }^{3}$. Appropriate duration of therapy for AOM is unclear; however, the typical course of therapy is 10 -days, but a 5 to 7 -day course may be adequate ${ }^{3}$.

Prevention of AOM is also important and is addressed in the AAP and AAFP guidelines. Lieberthal et al. (2013) ${ }^{3}$ state that prophylactic antibiotics for reduction of AOM occurrences in children with frequent AOM should not be prescribed by the clinician. These guidelines also suggest that annual influenza vaccines and pneumococcal conjugate vaccine should be recommended by the provider to all children based on the schedule of the Advisory
Committee on Immunization Practices. Other preventions that should be emphasized includes breastfeeding for 4-6 months should be encouraged as well as avoidance of tobacco smoke exposure to reduce occurrences of AOM.

\section{Current practice}

AOM is a localized and internal process which makes it very difficult for the clinician to determine the causative organism based on physical exam. As a result, it has often been routinely treated with antibiotics "just in case," which can put the client at risk for complications. In response, the AAP released revised guidelines for treatment of AOM which suggest initial observation in uncomplicated $\mathrm{AOM}^{3}$. The growing concern, though, is the lack of clinician compliance with these guidelines ${ }^{3}$. Inclusion of literature of clinical management of AOM or other disciplines.

One study discovered health care providers prescribed antibiotics for pediatric patients most of the time despite severity; this study included 100 participants that all had temperatures less than $102.2 \mathrm{~F}$ and no severe ear pain (five did have severe ear pain), and $92 \%$ received an antibiotic prescription. In this study, providers diagnosed AOM on this basis of one single finding such as erythematous tympanic membrane with no other signs, but a diagnosis of AOM should consist of findings of both middle ear effusion and inflammation ${ }^{6}$.

\section{Statement of the Problem}

Current practice does not reflect current guidelines for AOM diagnosis and management. Evidence based guidelines are available for treatment of $\mathrm{AOM}$, but they are not being followed. Following evidenced base guidelines leads to better outcomes for patients. Barriers for implementing these guidelines are not fully known, but it is important to identify these so that better care may be given to patients. Possible barriers include physicians' concern of follow-up, physicians' fear of complications, parental anxiety, lack of knowledge of guidelines, guideline or information overload, and ease of medication regimen. Further exploration of barriers is necessary for this study.

\section{Research Question}

The research question of this study is to determine what barriers affect the implementation of the 2004 American Academy of Pediatrics and American Academy of Family Physicians clinical practice guidelines for acute otitis media in the pediatric population.

\section{Rationale for the Study}

The purpose of this integrative review is to identify and examine current research on barriers of implementing the 2004 AAP and AAFP clinical practice guidelines for acute otitis media in pediatric population. Current research 
describes recommended guidelines, current practice, benefits and limitations of current recommendations. Few studies have addressed barriers associated with implementing the 2004 AAP and AAFP clinical practice guideline for acute otitis media in the pediatric population. An integrative review of the literature was performed to find what barriers exist among different disciplines of implementing current guidelines of AOM treatment.

\section{Methods}

This type of review calls for a comprehensive, systematic review of literature such as an integrative review. Other types of studies such as a systematic review, pilot study, or concept analysis would not be appropriate for study of this problem. Systematic reviews seek to answer a specific clinical question. There is not much research on this topic specifically related to our question, so we must utilize integration of several disciplines. The problem requires observation and identification of specific barriers related to lack of guideline compliance, so a pilot study would not be helpful and would be too time consuming. In addition, there is no intervention to test, which is the basis of pilot studies. Concept analysis studies seek to describe and explain vague concepts, which is not affiliated with this clinical problem.

Integrated reviews involve an in-depth investigation and critique of studies involving clinical problems that are relevant to advanced practice nursing. An integrative review is an appropriate approach for this project because it combines diverse methodologies such as quantitative and qualitative research to create a more well-rounded evidence review. It will allow incorporation of varied perspectives and support enhanced data collection strategies, as well as comparing discipline adherence and success rates. Disciplines included in this study are family practice, pediatrics, and ear, nose, and throat (ENT) disciplines. These disciplines were chosen as they encounter this issue the most of all disciplines. There will be more information available among these disciplines, leading to a comprehensive, integrated review of literature pertaining to them.

\section{Significance to Advanced Practice Nursing}

As this issue is one of the most common childhood illnesses as well as one of the most frequent reasons for antibiotic prescribing in the pediatric population, it is directly related to advanced practice nursing. Advance Practice Registered Nurses such as Family Nurse Practitioners are expected to practice evidence-based medicine. AOM is one of the most common childhood illnesses encountered in primary care. The disconnect between current guidelines and current practice produces a barrier for these providers. This is significant to advanced practice nursing because over usage of antibiotics creates unnecessary side effects, increased cost, unsatisfactory patient outcomes, and antibiotic resistance.

\section{Review of Literature}

Data collection involved a comprehensive search and review of literature including relevant information correlating with the inclusion criteria. Methods of research included utilizing Northwestern State University's online library database, Cumulative Index to Nursing and Allied Health Literature (CINAHL), Clinical Key by Elsevier, Google Scholar, Medical Literature Online (MEDLINE), independent searching of references from included and excluded articles, and wide internet searching for articles compiled with systematic reviews, cohort studies, randomized control trials, retrospective descriptive studies, surveys, and other descriptive and qualitative studies.

All articles were reviewed by title and abstract to determine relevance to the study. Studies that could not be determined through analysis of abstract and title only were further investigated through the body of the article. Once articles were reviewed, a thorough analysis of each article was completed and summarized in a literature review table. Research evidence was divided into hierarchy levels of research which determined the qualities of each article and were implemented throughout this study. Research levels I, II, III, and IV were included in this review of literature, incorporating the higher levels of information obtained. These research levels included observational surveys, retrospective descriptive studies, systematic reviews, cohort studies, survey analysis, randomized clinical trials, retrospective studies of databases, prospective randomized trials, analysis of randomized controlled studies, prospective interventional studies, and case-controlled trials. Levels V, VI, and VII of hierarchy research included retrospective analysis of patient records, surveys, data analysis, retrospective studies of databases, descriptive statistics of post-tests, semi-structured interviews, peer reviews, case series, decision analysis for outcome probabilities, and interpretive qualitative studies which were utilized only as supporting evidence to findings throughout the rest of this study.

\section{Inclusion and Exclusion Criteria}

The first inclusion criteria defined research studies that were focused on the diagnosis of AOM. This was then narrowed to pediatric populations, 6 months to 12 years of age. Each article was then further required to have been peer reviewed and written in the English language. Final inclusion criteria included AAP and AAFP clinical practice guidelines and adherence to practice.

Exclusions applied to this search included abstract-only articles, pediatric populations with significant medical 
comorbidities (prematurity, heart defects, asthma, and immunocompromise), otitis media with effusion, and any article referencing other guidelines for AOM that does not include the AAP and AAFP guidelines.

\section{Search Terms}

The following search terms where utilized in different Boolean phrase combinations in no particular order for each database: acute otitis media, adherence, barriers, practice guidelines, implementation, treatment outcomes, drug therapy, trends, otitis media physician adherence, parents, physicians' attitudes on otitis media, education, and complications.

\section{Electronic Search Methods}

Electronic searches were conducted utilizing Northwestern State University's online database library which included CINAHL, MEDLINE, and Clinical Key by Elsevier. Google Scholar was also utilized but produced duplicate articles previously discovered and did not permit any new referencing material.

\section{CINAHL}

A keyword search consisting of different configurations of acute otitis media, treatment outcomes, complications, implementation, barriers, adherence and practice guidelines through CINAHL were performed. Over 4,000 articles were found in this search. Inclusion criteria were applied to this initial search which narrowed the results to under 200 articles. Each of these articles was analyzed by review of its abstract and validated or removed from the study based on exclusion criteria. These articles were then analyzed based on hierarchy level of research to include in the review of literature.

\section{MEDLINE}

A keyword search consisting of multiple configurations of acute otitis media, adherence, practice guidelines, outcomes, physician compliance, implementation, treatment and trends was completed using the online MEDLINE database. Close to 5,000 articles were found using these search keywords. Inclusion criteria were applied with less than 300 articles remaining. These articles were then individually reviewed and either included or excluded based on criteria. The articles were again reviewed to identify the hierarchy levels of evidential research.

\section{Clinical Key by Elsevier}

A keyword search was conducted utilizing the Clinical Key by Elsevier database. Keywords utilized included multiple formulations of the following keywords: otitis media, adherence, otitis media physician adherence, parents, antibiotics, physicians' attitudes on otitis media, and guideline practice. This keyword search produced over 20,000 articles. Inclusion and exclusion criteria were applied to the search results and narrowed to 150 articles. These articles were individually reviewed through analysis of abstracts to further siphon through results to produce only the high levels of research to be discussed in the review of literature.

\section{Alternative Resources Utilized.}

Further research was conducted by utilizing references from articles that were included and excluded in this study to further validate research findings. These articles provide additional evidence in support of the identified high-level evidential research.

\section{Hierarchy Level Determination}

Melnyk, \& Fineout-Overholt $(2015)^{7}$ produced literature defining the different levels of hierarchy research which was utilized in this integrated review to provide high quality research and substantiate this research purpose. Melnyk, \& Fineout-Overholt $(2015)^{7}$ defined level I hierarchy of research to consist of systematic reviews and metanalysis of randomized controlled trials which can include guidelines based on systematic reviews and metanalyses. Level II of research hierarchy consists of one or more randomized controlled trials ${ }^{7}$. Level III of research hierarchy was defined as a controlled trial (Melnyk, \& Fineout-Overholt, 2015). Level IV of research hierarchy consists of case-controls or cohort studies ${ }^{7}$. Level $\mathrm{V}$ of research hierarchy entails descriptive and qualitative studies ${ }^{7}$. Level VI of research hierarchy contains single descriptive or qualitative studies ${ }^{7}$. Finally, level VII of hierarchy research comprises expert opinions ${ }^{7}$. This integrative review includes only levels I, II, III, and IV of hierarchy research to increase specificity and produce unambiguous results. Refer to Table 1 for further in-depth evaluation of the highest quality levels of research identified for the integration of barriers and the different disciplines recognized.

\section{Barriers Identified}

The introduction of the updated 2004 AAP and AAFP guidelines on treatment of AOM has brought forth multiple barriers among practitioners, parents of children with AOM, and clinical influences. These barriers prevent providers from implementing treatment guidelines in current practice. This research delves into identifying these barriers to guideline adherence for public awareness and concern for unnecessary antibiotic treatment. Each barrier was identified and described thoroughly after extensive and systematic investigation of literature pertaining to non-adherence with these guidelines. Major barriers identified included factors from providers, parents, AOM severity and complications, concerns for follow-up care, and other clinically related factors. Refer to Table 1 for an in-depth analysis of the studies identified and their research details and findings. 


\begin{tabular}{|c|c|c|c|c|c|}
\hline $\begin{array}{c}\text { Author(s) / } \\
\text { Year }\end{array}$ & $\begin{array}{l}\text { Design / } \\
\text { Hierarchy }\end{array}$ & Subjects & Findings & Relevance to Study & Barriers \\
\hline $\begin{array}{l}\text { Stewart, et al. } \\
(2001)\end{array}$ & $\begin{array}{l}\text { Design: } \\
\text { Observational } \\
\text { study through } \\
\text { survey } \\
\text { Hierarchy Level: } \\
\text { III }\end{array}$ & $\begin{array}{l}1,000 \text { surveys to } \\
\text { physicians }\end{array}$ & 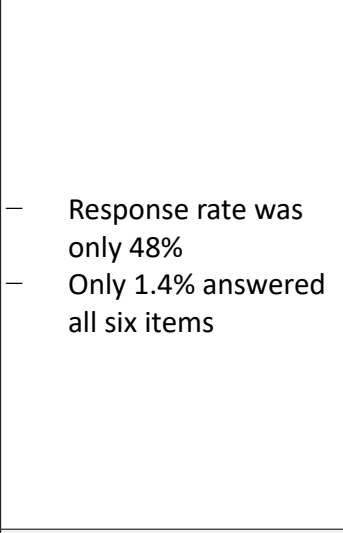 & $\begin{array}{l}\text { Clinical practice guidelines } \\
\text { have little effect on } \\
\text { changing physicians' } \\
\text { treatment patterns with } \\
\text { regards to AOM. }\end{array}$ & 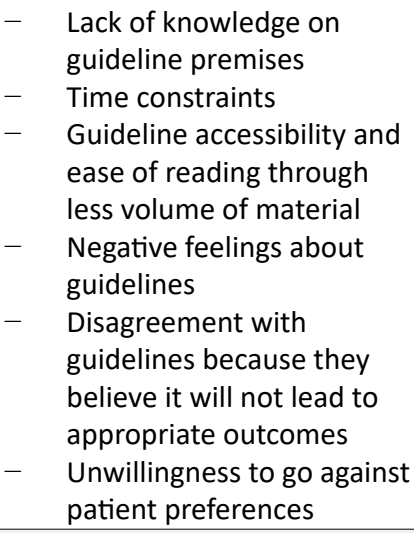 \\
\hline $\begin{array}{l}\text { Francis, et al. } \\
(2006)\end{array}$ & $\begin{array}{l}\text { Design: } \\
\text { Cohort study } \\
\text { Hierarchy Level: } \\
\text { II }\end{array}$ & $\begin{array}{l}153 \\
\text { pediatricians } \\
206 \text { internists } \\
127 \text { family } \\
\text { practitioners }\end{array}$ & 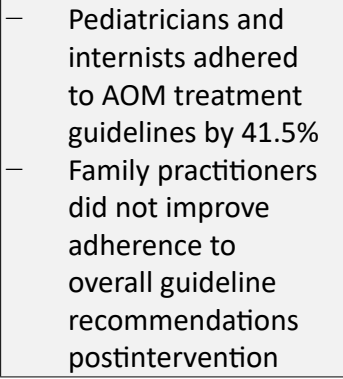 & $\begin{array}{l}\text { Primary care specialties } \\
\text { were more apt to adhere } \\
\text { to AOM treatment } \\
\text { guidelines after } \\
\text { interventional teaching of } \\
\text { such guidelines. }\end{array}$ & $\begin{array}{ll}- & \text { Complexity of patient care } \\
\text { - } & \text { Local and cultural } \\
\text { influences } \\
\text { - } & \text { Lack of education on } \\
\text { new guidelines in various } \\
\text { disciplines of medicine } \\
\text { practitioners }\end{array}$ \\
\hline \multicolumn{6}{|l|}{ (Continued) } \\
\hline $\begin{array}{c}\text { Author(s) / } \\
\text { Year }\end{array}$ & $\begin{array}{l}\text { Design / } \\
\text { Hierarchy }\end{array}$ & Subjects & Findings & Relevance to Study & Barriers \\
\hline $\begin{array}{l}\text { Boatright, } \\
\text { Holcomb, \& } \\
\text { Repogle (2015) }\end{array}$ & $\begin{array}{l}\text { Design: } \\
\text { Retrospective } \\
\text { descriptive } \\
\text { study } \\
\text { Hierarchy Level: } \\
\text { IV }\end{array}$ & $\begin{array}{l}100 \text { pediatric } \\
\text { patients ages } \\
6 \text {-months to } 12 \\
\text { years diagnosed } \\
\text { with non-severe } \\
\text { AOM }\end{array}$ & 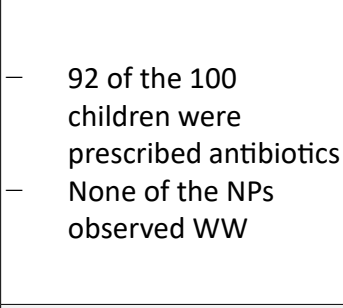 & $\begin{array}{l}\text { Health care providers are } \\
\text { not following the AAP } 2004 \\
\text { guidelines to diagnose and } \\
\text { treat AOM in children }\end{array}$ & $\begin{array}{ll}- & \text { Parental pressures } \\
- & \text { Lack of knowledge } \\
& \text { / understanding of } \\
& \text { guidelines } \\
- & \text { Lack of monitoring } \\
- & \text { Lack of recording pain } \\
& \text { severity } \\
- & \text { Policies }\end{array}$ \\
\hline $\begin{array}{l}\text { Fischer, et al. } \\
\text { (2007) }\end{array}$ & $\begin{array}{l}\text { Design: } \\
\text { Retrospective } \\
\text { study of } \\
\text { NHAMCS } \\
\text { databases } \\
\text { Hierarchy Level: } \\
\text { III }\end{array}$ & $\begin{array}{l}2.6 \text { million } \\
\text { pediatric } \\
\text { populations in } \\
1996 \text { with AOM } \\
\\
2.1 \text { million } \\
\text { pediatric } \\
\text { populations in } \\
2005 \text { with AOM }\end{array}$ & 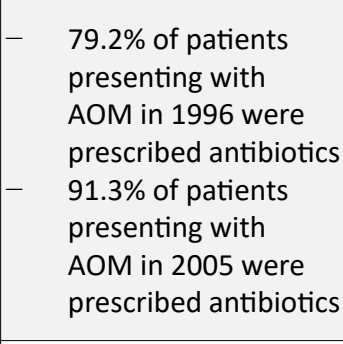 & $\begin{array}{l}\text { Antibiotic prescriptions for } \\
\text { AOM continue to increase } \\
\text { despite current } 2004 \text { AAP } \\
\text { and AAFP guidelines to } \\
\text { treat AOM in pediatric } \\
\text { patients. }\end{array}$ & $\begin{array}{l}\text { - Physicians do not believe } \\
\text { WW is appropriate in the } \\
\text { ED } \\
\text { - Physicians concerned } \\
\text { patients will not follow-up } \\
\text { closely as recommended in } \\
\text { guidelines }\end{array}$ \\
\hline $\begin{array}{l}\text { Schilder, et al. } \\
\text { (2017) }\end{array}$ & $\begin{array}{l}\text { Design: } \\
\text { Systematic } \\
\text { Review of } \\
\text { Randomized } \\
\text { clinical trials and } \\
\text { cohort studies } \\
\text { Hierarchy Level: } \\
\text { I }\end{array}$ & $\begin{array}{l}118 \text { relevant } \\
\text { articles }\end{array}$ & 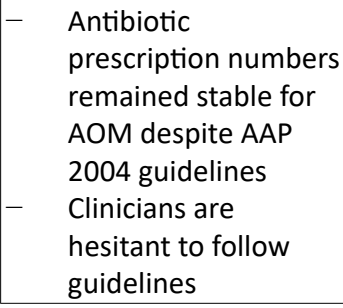 & $\begin{array}{l}\text { This study concluded that } \\
\text { the AAP and AAFP } 2004 \\
\text { guidelines to treat AOM in } \\
\text { pediatric populations are } \\
\text { not being implemented in } \\
\text { practice today. }\end{array}$ & $\begin{array}{ll}- & \text { Lack of physician's } \\
\text { knowledge on current } \\
\text { guidelines } \\
\text { - } \quad \text { Inaccurate diagnosis } \\
\text { due to lack of method to } \\
\text { classify severity of AOM }\end{array}$ \\
\hline
\end{tabular}




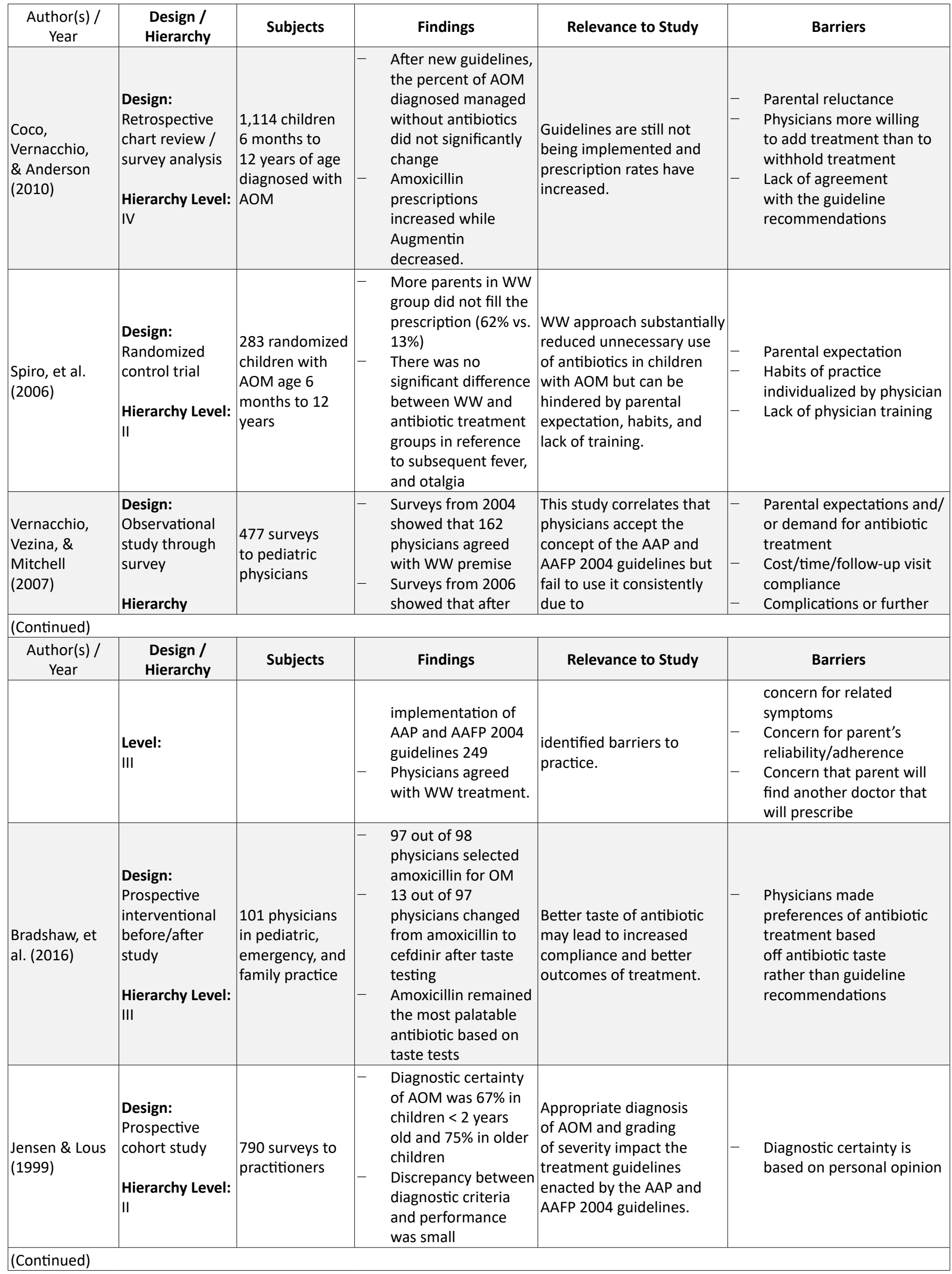




\begin{tabular}{|c|c|c|c|c|c|}
\hline $\begin{array}{c}\text { Author(s) / } \\
\text { Year }\end{array}$ & $\begin{array}{l}\text { Design / } \\
\text { Hierarchy }\end{array}$ & Subjects & Findings & Relevance to Study & Barriers \\
\hline $\begin{array}{l}\text { Chao, et al. } \\
\text { (2008) }\end{array}$ & $\begin{array}{l}\text { Design: } \\
\text { Prospective } \\
\text { randomized trial } \\
\text { Hierarchy Level: } \\
\text { I }\end{array}$ & $\begin{array}{l}232 \text { children age } \\
2-7 \text { years with } \\
\text { OM }\end{array}$ & $\begin{array}{l}\text { 87\% of parents } \\
\text { reported they did } \\
\text { not give their child } \\
\text { antibiotics or see } \\
\text { another physician } \\
\text { within the three-day } \\
\text { observation period } \\
\text { 66\% of parents in } \\
\text { the observation and } \\
\text { prescription group } \\
\text { gave their children } \\
\text { the antibiotic before } \\
\text { the three-day } \\
\text { observation period } \\
7-10-\text { day follow-up: } \\
81 \% \text { of parents in the } \\
\text { observation period } \\
\text { reported they did not } \\
\text { give antibiotics and } \\
53 \% \text { of parents in } \\
\text { the observation and } \\
\text { prescription group } \\
\text { did give antibiotics } \\
\text { 95\% of parents from } \\
\text { both groups were } \\
\text { satisfied with the } \\
\text { visit }\end{array}$ & $\begin{array}{l}\text { Parents that were given } \\
\text { a prescription were more } \\
\text { likely to fill it within the } \\
\text { first three observation days } \\
\text { after the visit contrary to } \\
\text { the advice of the physician. } \\
\text { This shows that physicians } \\
\text { do not believe parents will } \\
\text { be compliant with current } \\
\text { recommended AAP and } \\
\text { AAFP } 2004 \text { guidelines. }\end{array}$ & $\begin{array}{l}\text { - Physicians predict } \\
\text { nonadherence to WW and } \\
\text { will prescribe antibiotics } \\
\text { because they know the } \\
\text { parents want it }\end{array}$ \\
\hline \multicolumn{6}{|l|}{ (Continued) } \\
\hline $\begin{array}{c}\text { Author(s) / } \\
\text { Year }\end{array}$ & $\begin{array}{l}\text { Design / } \\
\text { Hierarchy }\end{array}$ & Subjects & Findings & Relevance to Study & Barriers \\
\hline $\begin{array}{l}\text { Vaz, et al. } \\
\text { (2015) }\end{array}$ & $\begin{array}{l}\text { Design: } \\
\text { Mailed surveys } \\
\text { Hierarchy Level: } \\
\text { III }\end{array}$ & $\begin{array}{l}707 \text { parents } \\
\text { with a child }<6 \\
\text { years old with } \\
\text { AOM responded } \\
\text { to surveys }\end{array}$ & $\begin{array}{l}\text { Knowledge gaps } \\
\text { are widespread } \\
\text { and more common } \\
\text { among parents } \\
\text { publicly insured } \\
\text { Insurance group } \\
\text { parents had high rates } \\
\text { of acceptable answers } \\
\text { regarding illnesses } \\
\text { in which antibiotics } \\
\text { are indicated but } \\
\text { were not good at } \\
\text { identifying illness } \\
\text { or symptoms which } \\
\text { antibiotics were } \\
\text { needed }\end{array}$ & $\begin{array}{l}\text { Parents are knowledgeable } \\
\text { in the need for antibiotics } \\
\text { to treat infection but are } \\
\text { uneducated when it comes } \\
\text { to specific symptoms } \\
\text { of illnesses that require } \\
\text { antibiotic treatment. }\end{array}$ & $\begin{array}{ll}\text { - } & \text { Deficit in parental } \\
\text { knowledge of antibiotic } \\
\text { indications }\end{array}$ \\
\hline $\begin{array}{l}\text { Bosley, et al. } \\
\text { (2017) }\end{array}$ & $\begin{array}{l}\text { Design: } \\
\text { Systematic } \\
\text { review } \\
\text { Hierarchy Level: } \\
1\end{array}$ & $\begin{array}{l}55 \text { full-text } \\
\text { articles were } \\
\text { reviewed }\end{array}$ & \begin{tabular}{|cl} 
& Four main themes: \\
- & Quality of \\
& relationships \\
& with healthcare \\
& providers \\
- & Dealing with \\
& conflicting \\
& messages \\
- & Rationalizing \\
& antibiotic use \\
- & parental \\
& practices from \\
& past experiences
\end{tabular} & $\begin{array}{l}\text { Parents want reassurance } \\
\text { and advice regarding their } \\
\text { children and illnesses. } \\
\text { Parents have poor } \\
\text { knowledge on appropriate } \\
\text { antibiotic utilization and } \\
\text { rely on past personal } \\
\text { experiences leading } \\
\text { physicians to continue } \\
\text { antibiotic treatment as } \\
\text { opposed to WW based on } \\
\text { AAP guidelines. }\end{array}$ & $\begin{array}{l}\text { Parents lack knowledge on } \\
\text { antibiotic indications }\end{array}$ \\
\hline & & & & & \\
\hline
\end{tabular}




\begin{tabular}{|c|c|c|c|c|c|}
\hline $\begin{array}{c}\text { Author(s) / } \\
\text { Year }\end{array}$ & $\begin{array}{l}\text { Design / } \\
\text { Hierarchy }\end{array}$ & Subjects & Findings & Relevance to Study & Barriers \\
\hline $\begin{array}{l}\text { Kautz- } \\
\text { Freimuth, et al. } \\
(2015)\end{array}$ & $\begin{array}{l}\text { Design: } \\
\text { Exploratory } \\
\text { survey through } \\
\text { descriptive } \\
\text { statistical } \\
\text { analysis } \\
\text { Hierarchy Level: } \\
\text { III }\end{array}$ & $\begin{array}{l}138 \text { parents } \\
\text { seeking } \\
\text { treatment for } \\
\text { their children } \\
\text { age } 2-7 \text { years- } \\
\text { old with AOM }\end{array}$ & 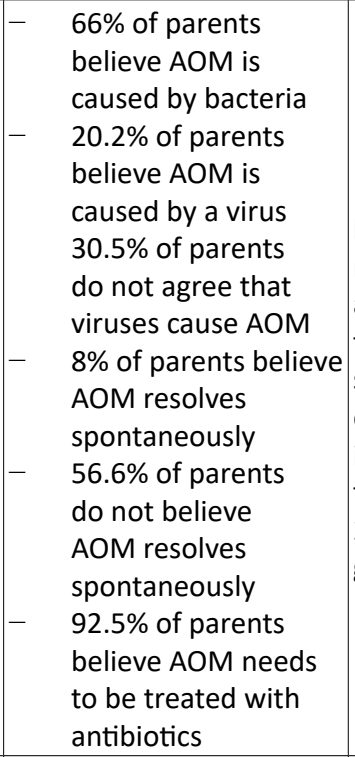 & $\begin{array}{l}\text { Uncertainties of parental } \\
\text { knowledge on AOM's } \\
\text { natural course and effects } \\
\text { antibiotics pose to those } \\
\text { that do not need them } \\
\text { solidify that parental } \\
\text { education is paramount } \\
\text { in physician adherence } \\
\text { to current AAP and AAFP } \\
2004 \text { treatment of AOM } \\
\text { guidelines. }\end{array}$ & 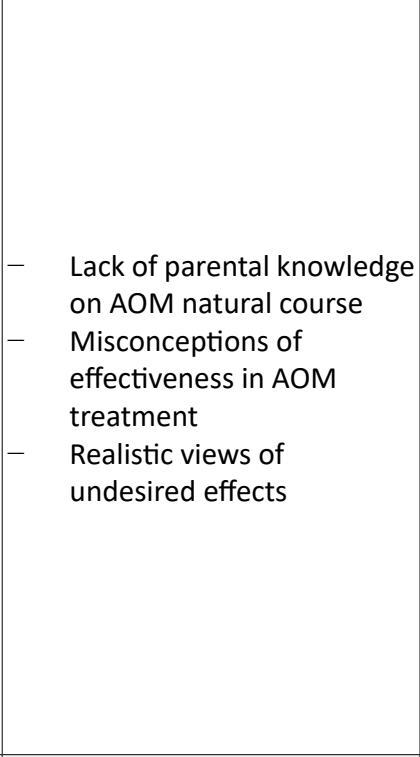 \\
\hline $\begin{array}{l}\text { McCormick, } \\
\text { et al. } \\
(2005)\end{array}$ & $\begin{array}{l}\text { Design: } \\
\text { Randomized } \\
\text { clinical trial } \\
\text { Hierarchy Level: } \\
\text { I }\end{array}$ & $\begin{array}{l}223 \text { children } 6 \\
\text { months to } 12 \\
\text { years old }\end{array}$ & 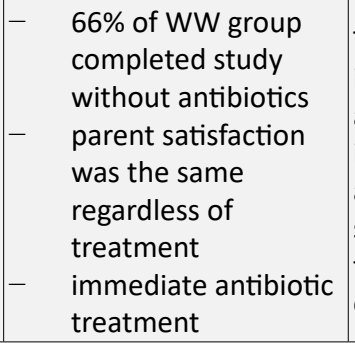 & $\begin{array}{l}\text { This study has shown that } \\
\text { implementation of AAP } \\
\text { and AAFP } 2004 \text { guidelines } \\
\text { is determinant on being } \\
\text { able to classify AOM } \\
\text { severity, further education } \\
\text { to physicians and parents } \\
\text { on risks and }\end{array}$ & 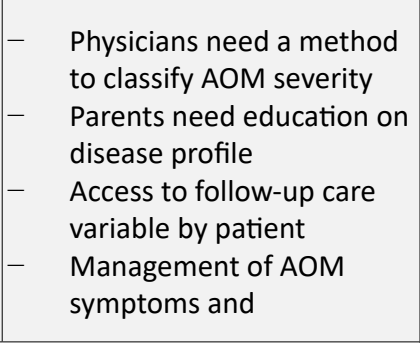 \\
\hline \multicolumn{6}{|l|}{ (Continued) } \\
\hline \multirow[t]{2}{*}{$\begin{array}{c}\text { Author(s) / } \\
\text { Year }\end{array}$} & $\begin{array}{l}\text { Design / } \\
\text { Hierarchy }\end{array}$ & Subjects & Findings & Relevance to Study & Barriers \\
\hline & & & $\begin{array}{l}\text { was associated with } \\
\text { decreased treatment } \\
\text { failures and } \\
\text { improved symptom } \\
\text { control but had } \\
\text { increased side effects } \\
\text { from treatment }\end{array}$ & $\begin{array}{l}\text { benefits of treatment } \\
\text { options, and compliance to } \\
\text { guidelines with access to } \\
\text { follow-up care. }\end{array}$ & compliance in question \\
\hline $\begin{array}{l}\text { Tahtinen, Laine, } \\
\text { \& Ruohola } \\
\text { (2017) }\end{array}$ & $\begin{array}{l}\text { Design: } \\
\text { Analysis of } \\
\text { randomized, } \\
\text { double blind, } \\
\text { placebo- } \\
\text { controlled trial } \\
\text { Hierarchy Level: } \\
\text { II }\end{array}$ & $\begin{array}{l}319 \text { children age } \\
6 \text { months to } 35 \\
\text { months of age } \\
\text { with AOM }\end{array}$ & 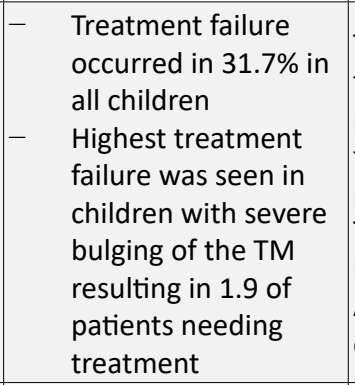 & $\begin{array}{l}\text { This study concluded } \\
\text { the unnecessariness of } \\
\text { prescribing antibiotics } \\
\text { for less severe AOM in } \\
\text { pediatric populations. } \\
\text { This affirms the need for } \\
\text { implementing AAP and } \\
\text { AAFP } 2004 \text { guidelines in } \\
\text { current practice. }\end{array}$ & $\begin{array}{l}\text { - Need for diagnostic criteria } \\
\text { to grade severity of AOM } \\
\text { uniformly }\end{array}$ \\
\hline $\begin{array}{l}\text { Sun, McCarthy } \\
\text { \& Liberman } \\
(2017)\end{array}$ & $\begin{array}{l}\text { Design: } \\
\text { Cohort study } \\
\text { Hierarchy Level: } \\
\text { II }\end{array}$ & $\begin{array}{l}250 \text { patients } \\
<18 \text { years old } \\
\text { with AOM in } \\
\text { the emergency } \\
\text { department }\end{array}$ & 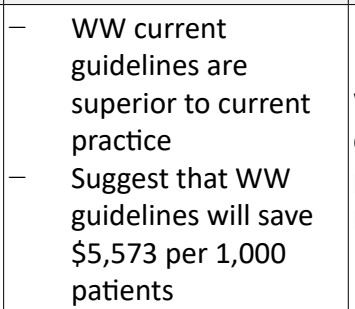 & $\begin{array}{l}\text { WW for AOM is more } \\
\text { cost-effective than current } \\
\text { practice and improves } \\
\text { patient outcomes }\end{array}$ & $\begin{array}{l}\text { No continuity of care } \\
\text { influencing decision- } \\
\text { making in emergency } \\
\text { departments }\end{array}$ \\
\hline
\end{tabular}




\begin{tabular}{|c|c|c|c|c|c|}
\hline $\begin{array}{l}\text { Author(s) / } \\
\text { Year }\end{array}$ & $\begin{array}{l}\text { Design / } \\
\text { Hierarchy }\end{array}$ & Subjects & Findings & Relevance to Study & Barriers \\
\hline $\begin{array}{l}\text { Laine, et al. } \\
\text { (2015) }\end{array}$ & $\begin{array}{l}\text { Design: } \\
\text { Randomized } \\
\text { controlled trial } \\
\text { Hierarchy Level: } \\
\text { I }\end{array}$ & $\begin{array}{l}281 \text { Children } 6 \\
\text { months to } 35 \\
\text { months old with } \\
\text { AOM }\end{array}$ & 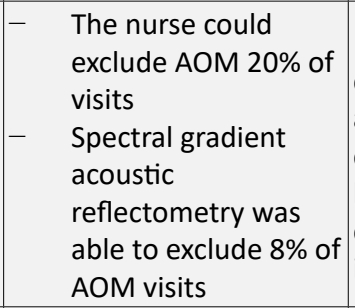 & $\begin{array}{l}\text { Nurses, if properly trained, } \\
\text { could help minimize costs } \\
\text { and increase provider } \\
\text { compliance with guidelines } \\
\text { by minimizing time } \\
\text { constraints from expensive } \\
\text { ineffective equipment. }\end{array}$ & $\begin{array}{l}\text { - Time constraints with } \\
\text { specialized otoscopy }\end{array}$ \\
\hline $\begin{array}{l}\text { Park, et al. } \\
(2008)\end{array}$ & $\begin{array}{l}\text { Design: } \\
\text { Case controlled } \\
\text { variable } \\
\text { comparison } \\
\text { Hierarchy Level: } \\
\text { II }\end{array}$ & $\begin{array}{l}36,585 \text { Children } \\
0-12 \text { years of } \\
\text { age with AOM } \\
\text { diagnosis in } \\
\text { identified } \\
\text { populations } \\
\text { based on sex, } \\
\text { race, season } \\
\text { and year of } \\
\text { diagnosis }\end{array}$ & \begin{tabular}{|l}
- \\
Positive relations \\
to the probability \\
of patients being \\
prescribed antibiotics \\
Higher cure rates \\
with severe AOM \\
cases and patient \\
comorbidities that \\
were prescribed \\
antibiotics rather \\
than WW patients \\
(82.34\%-74.44\%)
\end{tabular} & $\begin{array}{l}\text { This study demonstrates } \\
\text { treatment variation within } \\
\text { observational databases } \\
\text { can provide useful } \\
\text { information to implement } \\
\text { in policies for practices } \\
\text { to increase treatment } \\
\text { effectiveness. }\end{array}$ & $\begin{array}{l}\text { - Lack of policy to } \\
\text { implement guidelines in } \\
\text { practice }\end{array}$ \\
\hline
\end{tabular}

\section{Provider Factors}

Throughout the literature, specific provider barriers were the greatest motive for providers' lack of implementing AAP and AAFP guidelines in treating AOM in pediatric populations. Stewart, Manolidis, Wynn, and Bautista $(2001)^{8}$ identified multiple key provider factors that influence daily practice and have changed providers' behaviors in multiple specialties. Stewart et al. (2001) ${ }^{8}$ identified four main physician factors - knowledge, attitude, disagreement, and behaviors of practitioners not implementing AOM treatment guidelines. Physicians' lack of knowledge on current AAP and AAFP guidelines and its content was identified as part of time constraint due to volume of information available, guideline accessibility, and lack of distribution of knowledge among other disciplines ${ }^{8}$.

Francis, Beckman, Chamberlain, Partridge, and Greene $(2006)^{9}$ identified that information was not effectively shared amongst other disciplines of medicine including nurse practitioners and physician assistants. Boatright, Holcomb, and Replogle $(2015)^{6}$ conducted a retrospective descriptive study that found about $98 \%$ of patients were prescribed antibiotics. This study consisted of $16 \%$ nurse practitioners and $84 \%$ physicians which concluded that multiple disciplines continue to not follow guideline practices. Fischer, Singer, Lee, and Thode $(2007)^{10}$ found that emergency physicians were reluctant to endorse the AAP and AAFP guidelines not because they are not knowledgeable, but because they do not feel it is an appropriate strategy for the emergency department. Schilder et al. $(2017)^{11}$ suggested that adherence to practice guidelines of AOM are poorly followed because of lack of medical education. This study also proposes that the knowledge barrier may stem from insufficient educational interventions, cultural beliefs, social beliefs regarding antibiotic use, and inconsistency of diagnosing severity of $\mathrm{AOM}^{11}$. Many of the providers that have access and time to review these guidelines have negative feelings and disagree with these guidelines as they feel the guidelines can lead to a conglomeration of inappropriate patient outcomes. Coco, Vernacchio, Horst, and Anderson $(2010)^{12}$ found that physicians are more willing to adopt a recommendation from the guidelines to add a treatment rather than to withhold treatment. Stewart et al. $(2001)^{8}$ also found that there is little evidence to predict actual behaviors in practice compared with guideline recommendations due to individual case scenarios. Lack of training and education impact the effectiveness of AOM treatment and adherence to evidence-based guidelines in practice. Recent evidence suggests that continuing medical education is imperative to improve implementation of AOM guideline recommendations ${ }^{11}$.

Furthermore, Spiro et al. (2006) ${ }^{13}$ found that even when the AAP and AAFP guidelines recommend antibiotic therapy, physicians continue to not follow the guidelines by prescribing long-course antibiotic therapy instead of the recommended short-course. Vernacchio, Vezina, and Mitchell $(2007)^{14}$ also identified that physicians were reluctant to comply with guideline recommendations of high-dose amoxicillin-clavulanate due to the guideline straying from evidence of practice and associated infective pathogens. Bradshaw et al. $(2016)^{15}$ found in an interventional study that physicians were also more apt to prescribing certain antibiotics due to palatability after taste testing despite updated guideline recommendations. Jensen and Lous (1999) ${ }^{16}$ suggest that one barrier to 
practice stems from personal provider opinions and degree of certainty in diagnosing AOM in pediatric patients. Jensen and Lous (1999) ${ }^{16}$ suggest that diagnostic uncertainty could be reduced by more extensive use of pneumatic otoscopy and specified diagnostic criteria.

Finally, physician non-compliance with implementing the updated AAP and AAFP 2004 guidelines to treat AOM in pediatric populations is contributed to habits of practice ${ }^{13}$. Physicians in the United States have routinely prescribed antibiotics for AOM and believe many parents have become accustomed to and expect a prescription for treatment ${ }^{13}$. Vernacchio, Vezina, and Mitchell (2007) ${ }^{14}$ identified that poor patient outcomes are a result of parental reluctance to accepting the guidelines' watchful waiting approach. Chao, Kenkov, Reyes, Lichten, and Crain (2008) ${ }^{17}$ conducted a prospective randomized trial that found a physician's ability to predict adherence had a sensitivity of $21 \%$ and a specificity of $100 \%$. They also found that parents expressed resistance to treatment plan of observation with a prescription and an increased rate of noncompliance by $95 \%{ }^{17}$. Physicians are also skeptical to adhere to guidelines, fearing the parent will opt for another provider that will prescribe an antibiotic ${ }^{14}$.

\section{Parental Factors}

Another major barrier identified in physician nonadherence to the updated AAP and AAFP 2004 guidelines on AOM in pediatric populations were parental factors. Despite educational campaigns implemented to decrease misuse of antibiotics, deficits in parental knowledge continue $^{18}$. Parents experience anxiety and concern for their child's health and trust providers to care for their child $^{19}$. Multiple studies indicated that parents need further education on the natural course of AOM and realistic views on undesired effects and misconceptions of effective treatment. Bosley et al. (2017) ${ }^{19}$ found that parents relied on previous experiences with antibiotic treatment because they wanted to relieve their child's symptoms. Parents have also shown concern for deterioration of their child's condition if physicians do not prescribe antibiotics and comply with the recommended guidelines. This indicates a lack of knowledge and beliefs of parents with respect to causes and natural course of the illness as well as misconceptions concerning antibiotic effects $^{20}$. The study by McCormick et al. (2005) ${ }^{21}$ implied that lack of parental education regarding the risks and benefits of AOM treatment was a key factor in poor provider adherence to implementing treatment guidelines. As research demonstrates, it is imperative to implement readily accessible and easy-to-understand management options to improve parent's health literacy in treating AOM in pediatric populations.

Vernacchio, Vezina, and Mitchell $(2007)^{14}$ conducted a study that listed parents' reluctance to adhering to guidelines based on anxiety about observation and further demand antibiotic treatment. Previous practice amongst pediatricians was to routinely prescribe antibiotics for $\mathrm{AOM}^{13}$. This routine practice has influenced parents' ideals on AOM treatment and expect antibiotic treatment when their child has AOM symptoms ${ }^{13}$. Coco, Vernacchio, Horst, and Anderson (2010) ${ }^{12}$ found that parental reluctance to accepting the guideline recommendations is a major barrier to practitioner implementation. This cycle of parental expectation and provider willingness presents a significant barrier to implementing guidelines.

\section{AOM Severity / Complication Risk}

Certainty of AOM diagnosis is influenced by diagnostic equipment, provider's knowledge, and provider's experience with physical exam problems ${ }^{16}$. Tahtinen, Laine, and Ruohola (2017) ${ }^{22}$ conducted a randomized, doubleblind, placebo-controlled trial that concluded children with severe bulging of the tympanic membrane seemed to benefit from antimicrobial therapy. This research indicates that guidelines should also include specified criteria on diagnosing the severity of AOM to refrain from subjective observational opinions from physicians. Accurate diagnosis of AOM is a key factor for overdiagnosis and overtreatment with antibiotics against the AAP and AAFP recommendations ${ }^{11}$. McCormick et al. (2005) ${ }^{21}$ also suggest that physician compliance with implementing AOM treatment guidelines would be improved with an appropriate method to classify AOM severity. Vernacchio, Vezina, and Mitchell (2007) ${ }^{14}$ conducted mailed surveys that concluded a major barrier to practitioner adherence to AOM treatment guidelines included physicians' fear of children not improving within an acceptable time frame. This concern lead to physicians prescribing backup antibiotic therapy with parental follow-up strategies ${ }^{14}$. This leads to increased responsibility of parents and may not be appropriate for all families. McCormick et al. (2005) ${ }^{21}$ conducted a randomized clinical trial that discovered that the watchful waiting treatment from updated treatment guidelines are appropriate if the patient maintains a non-severe status and is kept comfortable with symptom management.

\section{Follow-up Concerns}

Physicians have identified difficulty associated with follow-up care for children managed initially with observation as an important barrier to AAP and AAFP guideline adherence ${ }^{14}$. Increased time and costs of care influence parental deterrence in complying with follow-up management ${ }^{14}$. Fischer, Singer, Lee, and Thode $(2007)^{10}$ conducted a retrospective study sampling emergency department visits that identified declines in guideline implementation of $\mathrm{AOM}$ treatment because providers 
felt they are not an appropriate strategy for treatment in the emergency department. Sun, McCarthy \& Liberman $(2017)^{23}$ also found during a cohort study that physicians are reluctant to complying with guidelines because of the need for close follow-up and risk of complications. A critical element of guideline practice about observational strategies is that close follow-up must be ensured so intervention with antibiotic therapy can be initiated if the patient's condition worsens ${ }^{10}$. Doubting patient follow-up often leads to cautious diagnostic and therapeutic plans in emergency settings that would otherwise be followed more closely in primary care settings ${ }^{17}$. McCormick et al. $(2005)^{21}$ suggest that guideline adherence in treating AOM must have access to follow-up care to receive effective continuance of care and appropriate antibiotic regimen if needed.

\section{Clinical Factors}

Patient complexity of treatment has been implicated in the lack of adherence to AOM guideline treatments by practitioners ${ }^{9}$. Pediatric patients generally have less comorbidities, but those children that present to practice with multiple comorbidities increase physician skepticism of following practice guidelines for all children as parents feel the need for treatment regardless of comorbidities ${ }^{9}$. Costs to patients and practice influence practitioner's decision to implement AOM guideline practices by weighing benefits and costs to both parties ${ }^{9}$. The magnitude of practitioner and patient cost trade-off was identified as insignificant to induce physicians to change new guidelines from long-held practices ${ }^{9}$. These long-held practices include personal opinions in diagnosis of AOM in pediatric populations. Jensen and Lous $(1999)^{16}$ identified a major barrier to practice guideline implementation among providers as a lack of specified diagnostic criteria of AOM leading to more diagnostic uncertainty. Local and cultural forces may impede or promote AOM treatment guideline adherence in practice ${ }^{9}$. Integrated combinations of cultural influences and self-reinforcing interventions are needed to empower and improve compliance with AOM treatment guidelines.

Stewart, Manolidis, Wynn, and Bautista $(2001)^{8}$ further discovered time constraints as a barrier to physicians' adherence to AOM treatment guidelines. With advanced technology more diagnostic tools are being utilized in practice, which may add to physician time constraint in learning to implement them into practice. Laine, Tahtinen, Ruuskanen, Loyttyniemi, and Ruohola (2015) ${ }^{24}$ also addressed the barrier of time constraints with diagnostic tool evaluations in their study.

Finally, another barrier identified was that facilities lack defined policies toward implementing AAP and AAFP recommendations to provider practice ${ }^{25}$. Park et al.
$(2008)^{25}$ concluded that policymakers should implement beneficial models of guideline practice recommendations and accumulate strengths from multiple clinical settings to maintain physician adherence to guidelines. Furthermore, suggesting policies with clinical scenarios that implement these guidelines can improve adherence and understanding of AAP and AAFP guidelines on treating AOM in pediatric populations ${ }^{25}$.

\section{Synthesis of Relevant Literature}

Findings of the synthesis of evidence findings was a major activity in this integrative review. In this section, information discussed will be divided into disciplines by comparing themes regarding barriers to implementation of the 2004 AAP and AAFP guidelines. Disciplines involved included Nursing, Family Practice, Pediatrics, and Ear, Nose, and Throat (ENT). Nineteen articles were included in the review of literature. Three articles related to nursing were included. There were five family practice articles included. Four articles were included in ambulatory or emergency care. Five of the articles were related to pediatric practice, and two included were focused on ENT. Many of these articles overlap with other disciplines, which was discussed in detail.

\section{Findings of Nursing Literature}

Pediatric Nursing journal published a study regarding treatment patterns and inaccurate prescribing by health care providers in relation to current guidelines. Boatright, Holcomb, and Repogle $(2015)^{6}$ orchestrated a retrospective descriptive study and found health care providers treated AOM based on one exam finding and they prescribed antibiotics more for pediatric patients, even those with nonsevere AOM, which was incongruent with current guidelines. Sixteen percent of the study participants were nurse practitioners, while $84 \%$ were physicians. No relationship was determined among these providers regarding treatment, but it was noted that no nurse practitioner utilized watchful waiting. These results, however, were not statistically significant. Boatright, Holcomb, and Repogle $(2015)^{6}$ suggested educational interventions, policy changes, and monitoring interventions should be implemented for better adherence to current guidelines.

Laine et al. (2015) ${ }^{24}$ found that a major barrier to following current guidelines of AOM diagnosis and management is time and the use of pneumatic otoscopy. This study sought to conclude whether trained nurses could rule out AOM in children after being trained in pneumatic otoscopy. The nurses' findings were compared to the control, the physician's findings. There were three criteria for diagnosis. The first was middle-ear effusion by at least two TM findings (bulging position, decreased or absent mobility, abnormal color, or opacity not related to 
scarring). The second criteria included acute inflammatory signs including at least one of the following: distinct reddened patches or streaks over a bulging or yellow tympanic membrane. Finally, the patient must also have had systemic signs or symptoms ${ }^{24}$. This study revealed that these tests performed by nurses were effective at ruling out AOM. Limitations to this study include uncooperative children and nurse inexperience.

Bosley et al. (2017) ${ }^{19}$ conducted a systematic review utilizing CINAHL, MEDLINE, PsycINFO, The Cochrane Library, British Nursing Index, EMBASE and PUBMED databases for primary articles published between 20062016. They determined that parents want reassurance and insight when caring for their children. However, parents had poor knowledge on the appropriate use of antibiotics as well as overprescribing dangers. Parents tended to use past experiences of children improving on antibiotics, and they thought when their child was ill that they needed an antibiotic to make them better. This study recommended specialized education for parents, incorporating adequate time, reassurance, easy-to-read information, education level of parent, and attitudes and practices of parents ${ }^{19}$.

\section{Findings of Family Practice Literature}

Park et al. $(2008)^{25}$ conducted a case-controlled variable comparison of antibiotic treatment for otitis media among family practice, general practice, pediatrics, otolaryngologists, and other specialties. This study stated that otitis media is the top cause for antibiotic prescribing in the U.S. and recognized that overprescribing leads to the spreading of antibiotic resistance, a serious problem. Approximately $33 \%$ of patients were treated with antibiotics by family practice physicians as opposed to $16 \%$ by pediatricians and $0.88 \%$ of otolaryngologists. Family practice had a higher probability of prescribing antibiotics than all other specialties. This study also found that patients living in areas of higher physician supply per capita had a greater chance of receiving an antibiotic prescription for treatment of AOM. Park et al. (2008) $)^{25}$ suggested that a policy for lowering unnecessary antibiotic prescribing is needed.

Francis et al. (2006) ${ }^{9}$ conducted a cohort study of pediatricians', family practitioners', and internists' adherence rates to otitis media practice guidelines following a multi-faceted intervention. This study found a statistically significant difference among these groups. They found pediatricians initially had the poorest baseline adherence rate than internists and family physicians, but they improved more than the other two disciplines. The intervention included targeted education, patientspecific outcomes data, feedback, and a financial incentive. Speculation of pediatricians' drastic improvement included a culture that promotes guideline adherence and a better knowledge of treating AOM. In contrast, family physicians did not have an encouraging culture of guideline promotion. Family practitioners also had worked with patients that have increased comorbid conditions than those of pediatrics, which lead to a more individualized decision than guidelines allow. Family physicians also seemed to focus on the individual experience as opposed to population-focused outcomes ${ }^{9}$.

One family practice study identified the barrier of diagnostic uncertainty due to unclear diagnostic standards $^{16}$ (Jensen \& Lous, 1999). Though this study was performed in 1999, the key variables remain true today. AOM is still one of the most common reasons for office visits in pediatrics, and there is still much diagnostic uncertainty accompanying AOM. This study paved the way for research that examines diagnostic uncertainty of AOM in children, being one of the first studies with that focus. They found that providers base their diagnosis of AOM on their own opinion, and their level of diagnostic uncertainty was high. The study proposed use of tympanometry and pneumatic otoscopy as possible means to eliminate this barrier; however, it was found that time constraints in family practice settings may prevent utilization of these methods of assessment ${ }^{16}$. A pediatric study by Tahtinen, Laine, and Ruohola (2017) ${ }^{22}$ elaborated on this barrier and concluded there was that a need for diagnostic criteria that would grade the severity of $\mathrm{AOM}$ in attempt to prevent unnecessary prescribing of antibiotics. This study was further discussed in the pediatric literature findings section.

\section{Findings of Emergency Care Literature}

AAP and AAFP endorsed clinical guidelines regarding $\mathrm{AOM}$ as discussed, but one study questioned whether those guidelines are relevant, safe, or effective for an emergency department (ED) setting. Fischer, Singer, Lee, and Thode $(2007)^{10}$ performed a retrospective study using national databases to determine the trend of antibiotic prescriptions from the ED for AOM before and after guideline publication. Through their research, evidence revealed that antibiotic prescribing rates increased by about 2\% from 1996 to 2005 . This is contrary to what should have happened; a decrease should have been noted. One important barrier related to this discipline is that the American College of Emergency Physicians (ACEP) has not endorsed this guideline. Other factors, such as uncertainty of close follow-up and severity of presentation to ED, were unique barriers to this discipline.

Spiro et al. (2006) $)^{13}$ conducted a randomized controlled trial related to current guidelines. They observed that most physicians in the United States are trained to routinely provide antibiotics due to training or parental pressures. The study sought to determine if wait-and-see prescription 
(WASP) would reduce antibiotic use. Children with AOM from age 6 months to 12 years in an ED were randomly assigned groups: WASP or standard prescription (SP). The WASP intervention included a written prescription for an antibiotic that would expire three days after the child's ED visit. Parents were given clear instructions and educated on circumstances to fill prescription. This study found that WASP intervention reduced antibiotic use by $56 \%$. This evidence is useful for ambulatory settings where there is no established relationship with the provider, and followup care is difficult. This study also presented barriers to guideline usage in this discipline and potential solutions.

Another study added to the concept of WASP, also known as watchful-waiting (WW). Sun, McCarthy, and Liberman $(2017)^{23}$ sought to determine the cost effectiveness of WW. They found through a retrospective review, including randomly selected charts of patients less than 18 years of age, that guidelines were not being followed. In the study population $(n=231), 93.5 \%$ were prescribed antibiotics, $2.8 \%$ were advised to undergo $\mathrm{WW}$, and $3.6 \%$ were sent home without an antibiotic. Of these patients, $42.1 \%$ met criteria for immediate antibiotic prescription while $57.9 \%$ were candidates for WW. This study added that ED care has challenges compared to primary care as encounters with patients are episodic in nature, and continuity of care is not feasible. WW necessitated patient follow-up, and education to providers and parents on appropriate treatment guidelines. This will reduce health expenditures, improve health outcomes, and be cost-efficient to society ${ }^{23}$.

Surprising results about parents were observed through a different study conducted in a pediatric ED. Chao et al. (2008) $)^{17}$ compared parental adherence to delayed antibiotic therapy with and without a physical prescription for AOM. Ultimately, parents accepted observation therapy as a valid treatment option; however, adherence was greater in the group that received observation therapy without a prescription than the group that received a written prescription. The study found that parents were more likely to fill the written prescription before three days contrary to provider advice and explained AAP guidelines. Barriers reported in this study include parental desire for antibiotics and perception that AOM is a condition that always requires antibiotics. Instead, a shift in thinking should be that this illness requires symptomatic care and close follow-up though it may be difficult for physicians and parents to accept ${ }^{17}$.

\section{Findings of Pediatric Literature}

One study observed trends in management since the release of the 2004 AAP and AAFP guidelines regarding AOM. Vernacchio, Vezina, and Mitchell $(2007)^{14}$ identified the most common barriers to physicians not implementing guidelines to be parental reluctance (83.5\%), cost, and difficulty of follow-up for those who did not improve (30.9\%). Though educational solutions to parental reluctance have been thought to be helpful, one study revealed deficits in parental knowledge exist despite these efforts ${ }^{18}$. Vernacchio, Vezina, and Mitchell (2007) ${ }^{14}$ found that though physicians accept observation as a valid treatment option for uncomplicated AOM, they only utilize it occasionally. In fact, providers that were most accepting of observation therapy include pediatricians (more than family physicians), younger physicians, and providers in suburban and urban non-inner-city locations. In this study, pediatricians reported to accepting guidelines $15.3 \%$ more often than family physicians.

Kautz-Freimuth et al. (2015) ${ }^{20}$ conducted a pediatric study that found parental reluctance as a key barrier in implementing guidelines appropriately. Like the emergency care studies, they implemented a watchful waiting prescription. Parents were educated on when to fill the watchful waiting prescription. Forty percent of parents were accepting of the "wait-and-see" prescription and only gave it to the child once symptoms had continued for two days or gotten worse. Parental reluctance is also a consistent barrier across disciplines.

A pediatric study was conducted to evaluate the safety, efficacy, acceptability, and costs of watchful waiting intervention or a non-antibiotic intervention for children with nonsevere $\mathrm{AOM}^{21}$. Results of the study concluded that $66 \%$ of patients in the WW group completed the study without using antibiotics. Patient and parent satisfaction among the two groups were the same. The results of this study reveal WW is an acceptable option to parents, reduces amount and cost of antibiotic prescriptions, and reduces multi-drug resistant bacteria in children after an AOM episode. McCormick et al. (2005) ${ }^{21}$ suggest that five factors are key to implementing these guidelines: a way to classify AOM severity, parent education, AOM symptom management, follow-up care access, and utilizing appropriate antibiotics when necessary.

An aspect of the 2004 guidelines includes pain management for AOM. Coco, Vernacchio, Horst, and Anderson $(2009)^{12}$ studied providers' management of AOM before and after guideline publication. They found that of the disciplines, pediatricians have significantly increased treating pain associated with AOM after guideline introduction. One reason for this may be that the substitution of an unnecessary antibiotic prescription with pain treatment alleviates parental concerns. This study found that providers do not agree with prescribing amoxicillin-clavulanate for severe infections, but they would rather prescribe a broader, safer drug such as cefdinir. This study also concluded that education on guidelines will not be enough to promote adherence to guidelines. 


\section{Findings of ENT Literature}

It is noted in the medical profession that specialists tend to be more aware of guidelines in their field than primary care providers. Stewart et al. (2001) ${ }^{8}$ sought to determine whether evidence-based practice guidelines were lower than expected among pediatricians, otolaryngologists, and pediatric otolaryngologists. In this study, adherence to guidelines was poor across disciplines; in fact, close to half of practice recommendations were inconsistent with guideline recommendations ${ }^{8}$. This study suggested that further information is needed concerning whether physicians were not aware of guidelines, whether physicians disagreed with guidelines, or whether other factors existed that lead to a decreased rate in adhering to guidelines.

A rigorous systematic review of randomized controlled trials and cohort studies provides additional information on this topic. Schilder etal. $(2017)^{11}$ explained that accurate diagnosis and treatment of otitis media is key to decreasing rates of overdiagnosis and overtreatment, and current practice shows suboptimal compliance to guidelines. This study found that general physicians, pediatricians, and otolaryngologists were equally noncompliant with treatment guidelines. They suggested barriers may be combated with educational programs, electronic health record feedback systems, and targeting specific scenarios of otitis media for research to achieve better adherence to guidelines.

\section{Findings Across Disciplines}

These disciplines share similar barriers when it comes to complying with the AAP AOM guidelines. For example, palatability of medications affected treatment compliance among the pediatric population, which is also true for AOM management. Bradshaw et al. (2016) ${ }^{15}$ studied prescribing preferences of physicians based on medication palatability. Emergency, family, and pediatric providers were included, and this study found that emergency physicians were more likely to change prescription preference based on taste of medication than pediatricians or family physicians. This may be due to greater familiarity of treating AOM among these disciplines ${ }^{15}$.

Other barriers the disciplines have in common include parental anxiety, knowledge deficit of providers and parents, time constraints, poor follow up, fear of complications, and use of watchful waiting as a solution to guideline implementation. There are also differences among the disciplines. For example, the nursing studies were the only studies to mention nurses as a solution to time constraint. ED follow up was more challenging than other disciplines. ED providers tend to change their prescribing preferences based on taste, and they were least compliant with guidelines. Pediatricians seemed the most compliant, followed by ENT and family practitioners based on this literature review.

\section{Integration of Major Findings}

Studies on AOM guideline adherence were organized and assessed in this review. Nineteen studies met inclusion criteria. This section discusses major findings after literature was studied. Consolidation of major areas of agreements and disagreements in the chosen fields are also discussed. Throughout all studies, it was obvious that evidence-based guidelines were not being followed. It was also clear that barriers exist, and through scrupulous review, those barriers were identified. There was not an abundance of literature pertaining to barriers of implementing the 2004 guidelines, which makes this study so unique.

\section{Areas of Agreement}

Areas of agreement are discussed first, which include similar barriers identified among the disciplines reviewed. Barriers related to attitudes and lack of knowledge from both parents and providers include: inability to coordinate continuity of care, lack of follow up, poor parental adherence to provider's advice, lack of parental or provider knowledge, fear of complications, legal liability, institutional policy, and parental anxiety. Additional barriers relating specifically to provider knowledge deficit include inaccurate diagnosis and poor adherence to pain management.

Additionally, this review of literature has revealed a common theme of improper prescribing of antibiotics among providers in the disciplines of study. Identified barriers related to following the established guidelines regarding appropriate antibiotic treatments include disagreement with guidelines, more convenient dosing schedule of medication, ability to use broader spectrum antibiotic, physicians' habit, taste of medication, and overload of guidelines.

\section{Areas of Disagreement}

Areas of disagreement include differences among the disciplines. All areas studied were noncompliant with guidelines, but pediatricians seem to be the most willing to change their behaviors. The culture of disciplines may be the cause of this. Fischer, Singer, Lee, and Thode (2007) ${ }^{10}$ discuss the culture of pediatrics as one that is most willing to learn when compared to family practice. The AAP and AAFP collaborated in establishing the 2004 AOM treatment guidelines which should encourage these disciplines to equally adopt the guidelines over any other discipline. Ambulatory care, on the other hand, does not endorse professional guidelines regarding AOM management.

Another area of difference is dependent upon the healthcare setting. For instance, ambulatory care centers 
such as urgent care clinics have difficulty following up with patients due to the nature of their setting. Patients treated in clinics such as family practice, pediatrics, and ENT have few problems with scheduling follow up appointments.

\section{Gaps in Research}

One of the major gaps in research identified was that there have been no studies indicating solutions for overcoming barriers that impede guideline adherence. However, there have been a few studies that have investigated a solution like a watchful waiting prescription for ambulatory settings with clear instructions on filling the prescription ${ }^{13}$. Other gaps in research were knowledge of a standard length of treatment time and a gold standard for diagnosis. Diagnosis was based on a variety of clinical findings. Mutually specified tests to determine AOM diagnosis could increase adherence to guideline practices.

There have been attempts to study outcomes of providing education to parents and providers. Many studies recommend an educational intervention as a solution. However, one study implemented a program of this nature and found that being familiar with guidelines does not always result in their adoption ${ }^{12}$. Schilder et al. $(2017)^{11}$ state that the power of education is insufficient, and this may be due to cultural or social beliefs. This study also recommends studying specific scenarios such as a weekend versus weekday visit, ambulatory care versus clinic setting, and family care versus specialist care.

Another gap in research is the appropriateness of antibiotic choices for AOM among providers. A large gap exists in choices of antibiotics and guideline recommendations ${ }^{14}$. Finally, more research is needed to understand the complexity of variables that influence providers to respond to guidelines in a positive way ${ }^{9}$.

\section{Conclusion of Finding}

The studies on AOM guideline adherence presented in this review presented areas of agreements and disagreements. Areas of agreement include parental knowledge, parental anxiety, provider knowledge, exam hinderances, and medication compliance. Areas of disagreement include setting, policy, and culture. The major findings of nineteen articles were discussed as they relate to the disciplines chosen, and gaps in the literature were identified. Some gaps in research include barriers to guideline adherence, diagnostic standardization, treatment length, educational interventions, and invoking positive change to guideline adoption in providers. In conclusion, these studies reveal that evidence-based guidelines are not being followed, and barriers to adhering to these guidelines exist.

\section{Implications for Practice}

AOM continues to be a common health problem in the pediatric population. As medicine advances, evidencebased practice is essential to for quality patient outcomes. Clinical practice guidelines are based upon the latest research findings and are created in order to assist providers in caring for patients with certain medical problems. Antibiotics have been used effectively as firstline treatment for AOM since the $20^{\text {th }}$ century. Liberal and unnecessary prescribing of antibiotics led to pathogens becoming resistant to antibiotics. Current practice guidelines promote conservative use of antibiotics in order to lessen the threat of resistance. In 2013, the AAP and AAFP revised the 2004 clinical practice guidelines specifically for the management of AOM.

\section{Summary}

The research question of this integrative review is to determine what barriers affect the implementation of the 2004 AAP and AAFP clinical practice guidelines for acute otitis media in the pediatric population. Numerous studies and literature reviews have been completed to understand various aspects of nonadherence to AOM guidelines, but very few reviews if any have attempted to identify all possible barriers to the guidelines. This integrative review is unique in that it discusses the parental and provider attitudes, diagnostic criteria, and treatment methods for the management of AOM. It has been demonstrated through this integrative review of the literature that multiple aspects of the AAP and AAFP clinical practice guidelines for the management of $\mathrm{AOM}$ in pediatric patients are not being followed by parents or by clinicians of various disciplines. This nonadherence has the potential to negatively impact patient health, increase costs to the patient, and contribute to the increasing problem of microbial resistance to antibiotics.

\section{Conclusions}

There are many reasons for nonadherence to the AAP and AAFP clinical practice guidelines for AOM management which apply to all areas of the client encounter. The reasons discussed in this literature review include physician and parental unacceptance of the recommendations, disagreement with the recommended antimicrobial, time constraints, lack of standardized diagnostic test, and fear of poor patient follow up or complications. These findings are significant for advanced practice nursing because the identification of existing barriers will assist in overcoming them. As guidelines are changed there is an expected change in behavior, so barriers should be identified before the guideline is implemented ${ }^{26}$. Additionally, education about the expected behavior change should occur in all components of the guideline including clinicians, patients, and organizations ${ }^{26}$. It is evident from this integrative review that prescribers should be self-aware of their own biases whether it is personal preference to prescribe 
antibiotics instead of watchful waiting or partiality to a specific antibiotic due to taste or easier dosing schedule, as well as their own limitations in diagnosing AOM. This review also demonstrates the importance of parental education on antibiotic resistance and rationale for current guidelines.

\section{Recommendations}

Accurate diagnosis of AOM is critical in the prevention of overdiagnosis and overtreatment of this common childhood illness. Currently, AOM is diagnosed based on a spectrum of clinical signs such as bulging TM, presence of middle ear effusion and sudden onset of symptoms. Studies of gold standard tests to confirm AOM diagnosis are recommended for future practice in order to establish a universal standardized method for diagnosis rather than basing the diagnosis on signs. Additional recommendations for future studies include prescriber's feedback for nonadherence to the guidelines, evaluation of parental understanding of AOM pathogenesis and antimicrobial properties, interventions for changing behavioral practice of providers, and strategies to increase provider and parental guideline adherence.

\section{Acknowledgment}

This research was supported by Northwestern State University of Louisiana in completion of the Master's Degree Program in Nursing. We thank our colleague, Robyn Ray, DNP, APRN, FNP-BC, from Northwestern State University of Louisiana who provided insight and expertise that greatly assisted this research.

\section{Conflict of Interest Statement}

This document seeks to provide a high level of research review to identify barriers across medical care disciplines that hinder adherence of AOM guidelines in diagnosis and treatment of pediatric populations. Conflicts and potential conflicts of interest were identified including prior research on topic, utilization of personal research, application of previously published research, and personal bias in regard to research used. No research was utilized for personal gain. Research was not conducted for financial or non-financial interests and relationships.

\section{References}

1. Spiro DM, Arnold DH. Acute otitis media. Pediatric decision making. St Louis MO Mosby. 2011) doi: 10.1001/jama.296.10.1235

2. World Health Organization (WHO). Antimicrobial resistance. 2011. Retrieved from http://www.who.int/mediacentre/factsheets/fs194/ en/

3. Lieberthal AS, Carroll AE, Chonmaitree T, et al. Clinical practice guidelines: The diagnosis and management of acute otitis media. Pediatrics. 2013; 131(3): e964-e999. doi: 10.1542/peds.2012-348

4. Hirst $S$, Neill S. Treatment of acute otitis media in childhood. Practice Nursing. 2013; 24(8): 407-410. doi: 10.12968/pnur.2013.24.8.407
5. Thomas JP, Berner R, Zahnert T, et al. Acute Otitis Media-a Structured Approach. Deutsches Aerzteblatt International. 2014; 111(9): 151160. doi: 10.3238/arztebl.2014.0151

6. Boatright C, Holcomb L, Replogle W. Treatment patterns for pediatric acute otitis media: A gap in evidence-based theory and clinical practice. Pediatric Nursing. 2015; 41(6): 271-276. Retrieved from: http://web.a.ebscohost.com.nsula.idm.oclc.org/ehost/pdfviewer/ pdfviewer?vid=8\&sid=b4d6436f-d01f-4bb5-8458-d7f66383c2c5\%4 0sessionmgr4006

7. Melnyk BM, Fineout-Overholt E. Evidence-based practice in nursing \& healthcare: A guide to best practice (3rd ed.). Philadelphia PA Wolters Kluwer Health. 2015.

8. Stewart MG, Manolidis S, Wynn R, et al. Practice patterns versus practice guidelines in pediatric otitis media. Otolaryngology-Head \& NeckSurgery. 2001;124(5): 489-495. doi:10.1067/mhn.2001.115497

9. Francis DO, Beckman $\mathrm{H}$, Chamberlain J, et al. Introducing a multifaceted intervention to improve the management of otitis media: How do pediatricians, internists, and family physicians respond. American Journal of Medical Quality. 2006; 21(2): 134-143. doi: $10.1177 / 1062860605285276$

10. Fischer T, Singer A, Lee C, et al. National trends in emergency department antibiotic prescribing for children with acute otitis media, 1996 2005. Academic Emergency Medicine. 2007; 14(12): 1172-1175. doi: 10.1197/j.aem.2007.07.011

11. Schilder AG, Marom T, Bhutta MF, et al. Panel 7: Otitis media: Treatment and complications. Otolaryngology-Head \& Neck Surgery. 2017; 156S88-S105. doi:10.1177/0194599816633697

12. Coco A, Vernacchio L, Horst M, et al. Management of acute otitis media after publication of the 2004 AAP and AAFP clinical practice guideline. Pediatrics. 2010; 125(2): 214-220. doi:10.1542/peds.2009-1115

13. Spiro DM, Tay KY, Arnold DH, et al. Wait-and-see prescription for the treatment of acute otitis media: A randomized controlled trial. JAMA: Journal of the American Medical Association. 2006; 296(10): 12351241. doi: 10.1001/jama.296.10.123

14. Vernacchio L, Vezina RM, Mitchell AA. Management of acute otitis media by primary care physicians: Trends since the release of the 2004 American Academy of Pediatrics/American Academy of Family Physicians clinical practice guidelines. Pediatrics. 2007; 120(2): 281287. doi:10.1542/peds.2006-3601

15. Bradshaw H, Mitchell MJ, Edwards CJ, et al. Medication palatability affects physician prescribing preferences for common pediatric conditions. Academic Emergency Medicine. 2016; 23(11): 12431247. doi:10.1111/acem.13020

16. Jensen PM, Lous J. Criteria, performance and diagnostic problems in diagnosing acute otitis media. Family Practice. 1999; 16(3): 262-268. https://doi.org/10.1093/fampra/16.3.262

17. Chao JH, Kunkov S, Reyes LB, et al. Comparison of two approaches to observation therapy for acute otitis media in the emergency department. Pediatrics. 2008; 121(5): e1352-6. doi:10.1542/ peds.2007-2278

18. Vaz LE, Kleinman KP, Lakoma MD, et al. Prevalence of parental misconceptions about antibiotic use. Pediatrics. 2015; 136(2): 222231. doi: $10.1542 /$ peds.2015-0883

19. Bosley H, Henshall C, Appleton JV, et al. A systematic review to explore influences on parental attitudes towards antibiotic prescribing in children. Journal of Clinical Nursing. 2017; 2018(27): 892-905. doi: 10.1111/jocn.14073

20. Kautz-Freimuth S, Redaelli M, Samel C, et al. Parental views on acute otitis media (AOM) and it's therapy in children-results of an exploratory survey in German childcare facilities. 2015; 15(199). doi: 10.1186/s12887-015-0516-3 
21. McCormick DP, Chonmaitree T, Pittman C, et al. Nonsevere acute otitis media: A clinical trial comparing outcomes of watchful waiting versus immediate antibiotic treatment. Pediatrics. 2005; 115(6): 1455-1465. doi: 10.1542/peds.2004-1665

22. Tähtinen PA, Laine MK, Ruohola A. Prognostic factors for treatment failure in acute otitis media. Pediatrics. 2017; 140(3): 1-9. doi:10.1542/peds.2017-0072

23. Sun D, McCarthy TJ, Liberman DB. Cost-effectiveness of watchful waiting in acute otitis media. Pediatrics. 2017; 139(4): 1-9. doi: 10.1542/peds.2016-3086

24. Laine MK, Tähtinen PA, Ruuskanen 0, et al. Can trained nurses exclude acute otitis media with tympanometry or acoustic reflectometry in symptomatic children? Scandinavian Journal of Primary Health Care. 2015; 33(4): 298-304. http://dx.doi.org/10.3109/02813432.2015.1 118835

25. Park TR, Brooks JM, Chrischilles EA, et al. Estimating the effect of treatment rate changes when treatment benefits are heterogeneous: Antibiotics and otitis media. Value In Health. 2008; 11(2): 304-314. doi: 10.1111/j.1524-4733.2007.00234.x

26. Célind J, Södermark L, Hjalmarson 0 . Adherence to treatment guidelines for acute otitis media in children. The necessity of an effective strategy of guideline implementation. International Journal of Pediatric Otorhinolaryngology. 2014; 78(7): 1128-1132. doi: $10.1016 /$ j.ijporl.2014.04.029 